DEPARTMENT OF THE INTERIOR

UNITED STATES GEOLOGICAL SURVEY

\title{
AEROMAGNETIC MAP OF THE BIG MOOSE QUADRANGLE HERKIMER AND HAMILTON COUNTIES, NEW YORK \\ By
}

James R. Balsley and Randolph W. Bromery

GEOPHYSICAL INVESTIGATIONS

MAP GP-504

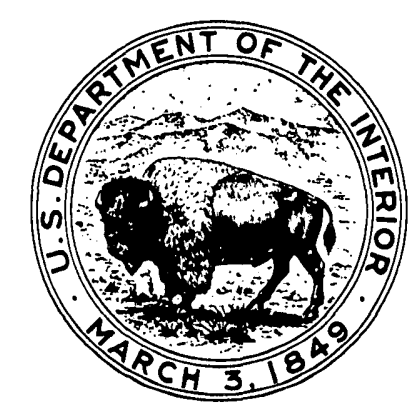

PUBLISHED BY THE U. S. GEOLOGICAL SURVEY

WASHINGTON, D.C. 